\title{
Quantitative Estimation of Porcine Endogenous Retrovirus Release from PK15 Cells
}

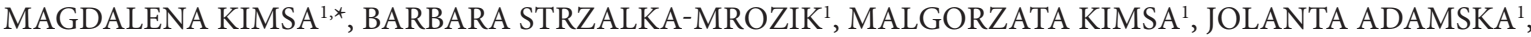 \\ JOANNA GOLA ${ }^{1}$, KRZYSZTOF LOPATA ${ }^{1}$ and URSZULA MAZUREK ${ }^{1}$
}

${ }^{1}$ Department of Molecular Biology, Medical University of Silesia, Narcyzow 1, 41-200 Sosnowiec, Poland

Received 10 April 2012, revised 7 July 2012, accepted 9 July 2012

\begin{abstract}
The present study focuses on the assessment of porcine endogenous retrovirus (PERV) release from PK15 cells in a time dependent manner. The highest amount of PERV A RNA was detected in PK15 cells after 16 hours of culture. The highest amount of PERV B RNA was detected in PK15 cells after 20 hours. The highest amount of both subtypes RNAs was detected in culture medium after 32 hours of culture. The peaks of PERV reverse transcriptase (RT) activity were detected after $28 \mathrm{~h}$ of culture in PK15 cells and after 32 hours in the culture medium. The monitoring of PERV release from PK15 cell line may be useful for the evaluation of PERV replication.
\end{abstract}

Ke y w o rd s: dynamics, PERVs, PK15 cell culture, real time QRT-PCR

Transplantation has been proved to be in many cases very successful treatment, however limited availability of appropriate organs and tissues induces the search for alternative sources (Lechler et al., 2005, Salim et al., 2006; Fiorelli et al., 2011). Pigs appear to be the most suitable animals that can be used as donors of cells, tissues and organs for human recipients (Jasinski et al., 2006; Cozzi et al., 2008), but immunological and biological barriers constitute the main obstacles of interspecies transplantation (Cozzi et al., 2008).

The prevalence of porcine endogenous retroviruses (PERVs), which are permanently integrated in the genome of all pigs, involves the risk of a zoonotic viral infection (Scobie and Takeuchi, 2009). A prolonged contact of the human body with the animal tissue infected with the pathogens, and the use of immunosuppressive drugs after grafting may facilitate pathogen adaptation and transmission to transplant recipients. PERVs can be released as infectious particles from different pig cells (McIntyre etal., 2003; Cunningham et al., 2004), and their infectivity is tightly connected with the dynamics of endogenous retroviruses production from host cells. Normal epithelial porcine kidney cells (PK15 cell line) seem to be an easily available model to study PERV release. The demonstration of the PERV dynamics may provide guidelines for the development of novel treatment strategies for potential PERV infection. Therefore, the present study focuses on the assessment of PERV release from PK15 cells in a time dependent manner. The quantitative monitoring of PERVs may be also useful for the evaluation of their replication activity.

A PK15 cell line (ATCC CCL-33) was obtained from the American Type Culture Collection and routinely maintained in the DMEM medium (Dulbecco's Modified Eagle Medium; Lonza, Basel, Switzerland), supplemented with $10 \%$ fetal bovine serum (FBS; Lonza, Basel, Switzerland) and gentamicin $25 \mathrm{mg} / 100 \mathrm{ml}$ (Lonza, Basel, Switzerland). PK15 cells were seeded into 12-well culture plates (Nunc, Wiesbaden, Germany) at a density of $1 \times 10^{4}$ cells per well. Medium and cells were collected at the start of the experiment $(0 \mathrm{~h})$ and after 4 , $8,10,12,16,20,24,28,30,32,34,36,38$ and 40 hours. The cell-free supernatants were obtained by filtration through 0.45-mm-pore-size membranes.

Genomic DNA extraction was performed with a commercially available kit QIAamp DNA Mini Kit (Qiagen, Valencia, CA), according to the manufacturer's instructions. Total RNA was extracted from harvested cells and the medium using the phenol-chloroform method (Chomczynski and Sacchi, 1987). The quality of isolated nucleic acids was checked using $0.9 \%$ agarose gel stained with ethidium bromide (SigmaAldrich, St. Louis, MO). Nucleic acids concentration was determined using GeneQuant II RNA/DNA spectrophotometer (Pharmacia Biotech, Cambridge, UK).

\footnotetext{
* Corresponding author: Magdalena Kimsa, Department of Molecular Biology, Medical University of Silesia, Narcyzow 1, 41-200 Sosnowiec, Poland; phone: +48 3236410 26; fax: +48 3236410 20; e-mail address: magdakimsa@gmail.com
} 
The respective copy numbers of PERV A, PERV B DNA and PERV A, PERV B RNA were evaluated using real-time Q-PCR and SYBR Green I chemistry (SYBR Green QuantiTect PCR Kit, QIAGEN, Valencia, CA) and real-time QRT-PCR and SYBR Green I chemistry (SYBR Green QuantiTect RT-PCR Kit, Qiagen, Valencia, CA), respectively. The analyses were performed using an Opticon ${ }^{\mathrm{Tu}}$ DNA Engine Continuous Fluorescence Detector (MJ Research, Watertown, MA). All samples were assayed in triplicate. Since the detection of PERV sequences in the culture medium could depend on the presence of residual pig cells, specific detection of the porcine cellular GAPDH gene and porcine mitochondrial DNA (mtDNA) was carried out. GAPDH was also included as an endogenous positive control of amplification and integrity of extracts. The following sequences of oligonucleotide primers, which are specific for the env gene of a particular subtype of PERVs and were described previously by Bösch et al. (2000), were applied: PERV A 5'-GAGATGGAAAGATTGGCAACAGCG-3' (sense), 5'-AGTGATGTTAGGCTCAGTGGGGAC-3' (antisense); PERV B 5'-AATTCTCCTTTGTCAATTCCGGCCC-3' (sense), 5'-CCAGTACTTTATCGGGTCCCACTG-3' (antisense). Detection of the porcine GAPDH gene was performed according Machnik et al. (2010), and the following sequences of oligonucleotide primers were applied: 5'-TGTCGCCATCAATGACCCC-3' (sense), 5'-TGACAAGCTTCCCATTCTC-3' (antisense), and porcine mtDNA was detected according to Moon et al. (2010), with primers: 5'-CTGAGGAGCTACGGTCATCACAAIIIIICTATCAGCT-3' (sense), 5'-TAGGGTTGTTGGATCCGGTTTCIIIIIGGAATAGGA-3' (antisense) (I - inosine bases).

The thermal profile for Q-PCR was as follows: polymerase activation at $95^{\circ} \mathrm{C}$ for $15 \mathrm{~min}$ and then 45 cycles consisting of the following temperatures and time intervals: $94^{\circ} \mathrm{C}$ for $30 \mathrm{~s}, 65^{\circ} \mathrm{C}$ for $45 \mathrm{~s}$ and $72^{\circ} \mathrm{C}$ for $40 \mathrm{~s}$. The thermal profile for one-step QRT-PCR was as follows: reverse transcription at $50^{\circ} \mathrm{C}$ for $30 \mathrm{~min}$, polymerase activation at $95^{\circ} \mathrm{C}$ for $15 \mathrm{~min}$ and then 30 cycles consisting of the following temperatures and time intervals: $94^{\circ} \mathrm{C}$ for $30 \mathrm{~s}, 65^{\circ} \mathrm{C}$ for $45 \mathrm{~s}$ and $72^{\circ} \mathrm{C}$ for $40 \mathrm{~s}$.

Specificity of PCR reaction and absence of the primer dimers were confirmed by determing the char- acteristic melting temperature ( $\mathrm{Tm}$ ) of each amplimer. The PCR products were also separated on $6 \%$ polyacrylamide gel and visualized by silver staining.

Reverse transcriptase activity in the supernatant and harvested cells at the start of the experiment $(0 \mathrm{~h})$ and after $4,8,10,12,16,20,24,28,32$ hours, respectively, was measured using a commercial assay (Cavidi-Tech, Uppsala, Sweden) according to the manufacturer's instructions.

Statistical analyses were performed using Statistica v 9.0 PL software (StatSoft, Tulsa, Oklahoma). P values below 0.05 were considered statistically significant. Values were expressed as median $(\mathrm{Me})$ with the $25^{\text {th }}$ and $75^{\text {th }}$ quartiles. Non-parametric tests were used for statistical analyses because the Shapiro-Wilk test indicated that the data were not normally distributed. The Mann-Whitney U test was used to compare the copy number of PERV DNA in PK15 cells. The Friedman and the Wilcoxon tests were applied to assess differences in the copy number of PERV in PK15 cells and the medium during the culture.

Analysis revealed that the copy number of PERV A DNA was significantly higher than PERV B DNA in PK15 cells. The copy number of PERV A RNA was also significantly higher than that of PERV B in tested cells (Table I). In the culture medium, a statistically significant relation between viral DNA of PERV A and PERV B was not found. However, a significant difference was observed between viral RNA of PERV A and PERV B (Table I). All samples of the culture medium were found to be negative for the porcine GAPDH DNA and mtDNA, thus the possibility of contamination with residual porcine cells was excluded.

At the next step, time dependent changes in the RNA level of PERVs in the PK15 cell line were assessed. Statistically significant alterations of the copy numbers of PERV A ( $\mathrm{p}=0.00012$, Friedman test $)$ and PERV B RNA $(p=0.00012$, Friedman test $)$ were observed. However, the differences in the copy number of PERV A $(p>0.05$, Wilcoxon test) and PERV B RNA ( $p>0.05$, Wilcoxon test) between the subsequent time points were not statistically significant. There was observed a stable release of PERV particles over a 40 hour period. The highest number of viral RNA of PERV A and PERV B in PK15 cells was detected after 16 and 20 hours, respectively

Table I

The quantitative relations between the copy number of PERV DNA and PERV RNA in the PK15 cell line and in the culture medium

\begin{tabular}{|c|c|c|c|c|c|c|c|c|}
\hline & \multicolumn{4}{|c|}{ PK15 cells (copy number/1000 cells) } & \multicolumn{4}{|c|}{ Culture medium (copy number/ml medium) } \\
\hline & PERV A & & PERV B & $\mathrm{p}^{*}$ & PERV A & & PERV B & $\mathrm{p}^{*}$ \\
\hline DNA & $22904(16216-31942)$ & $>$ & $7383(5968-11456)$ & $\mathrm{p}<0.0001$ & $1366(530-2599)$ & $>$ & $863(398-1582)$ & NS \\
\hline RNA & $1059974(439580-2462898$ & $8)>4$ & $43175(248490-78715$ & $\mathrm{p}=0.028 \quad 1$ & $4292(7697625-207$ & & $33(2490295-1$ & $=0.005$ \\
\hline
\end{tabular}

Statistical significance: $\mathrm{p}^{*}<0.05 ; \mathrm{p}^{*}-$ Mann-Whitney U test; NS - not significant

Median with the $25^{\text {th }}$ and $75^{\text {th }}$ quartiles are presented 

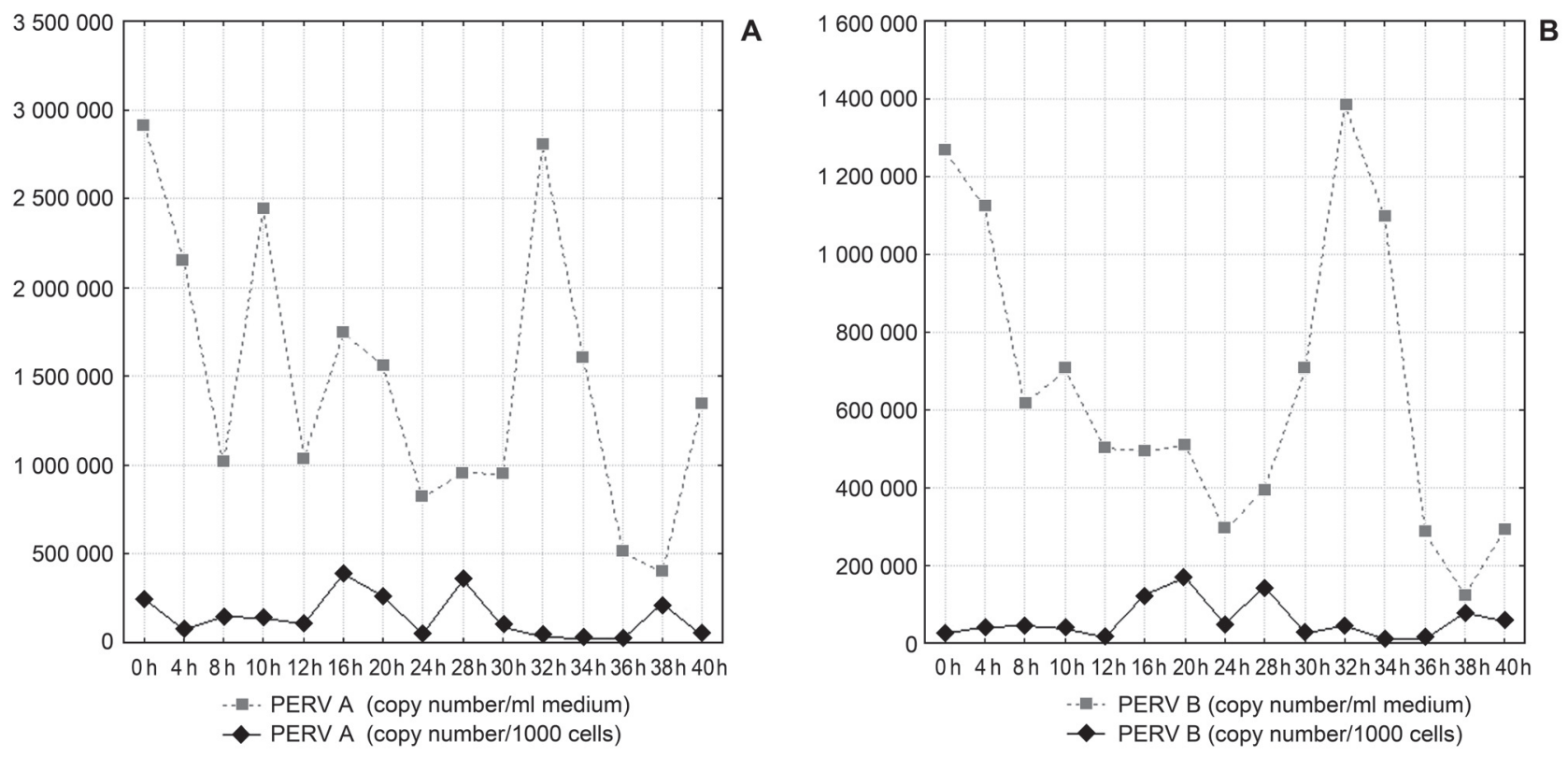

Fig. 1. The copy number of PERV A RNA (A) and PERV B RNA (B) in PK15 cells and the medium in the successive hours of culturing

(Figure 1A, Figure 1B, respectively). These changes in the level of virus RNA mirrored the alterations of the virus RNA in the culture medium. For the medium derived from the PK15 cells culture, the relations between the copy numbers of PERV A ( $\mathrm{p}=0.00012$, Friedman test) and PERV B RNA ( $p=0.00012$, Friedman test) during all analyzed time points were similar. The highest increase in viral RNA of PERVs was noticed after 32 hours (Figs 1A, 1B).

During the next part of the study, the reverse transcriptase (RT) activity in PK15 cells and a cell culture supernatant was determined. We assayed RT activity from samples collected at the same time point as samples used for PERV RNA quantitative assays. Time dependent changes of RT activity in PK15 cells, as well as in the culture medium, were detected, with the peaks of PERV A and B RT activity in PK15 cells after 28 and 32 hours of culture, respectively (Fig. 2).

Since there are not enough human organs for allogeneic grafts, we need to look for alternative sources of organs. However, the endogenous retroviruses, permanently embedded in the genome of pigs, may be extremely important in this respect. They are not pathogenic for a host organism, but the role of PERVs in the pathogenesis of human diseases has been unknown so far. Moreover, until now the risk of PERV transmission to human cells in vivo is still unclear (Garkavenko et al., 2004, Heneine et al., 2001; Levy et al., 2007, Switzer et al., 2001; Valdes-Gonzalez et al., 2010).

The presence of PERVs in various porcine cells and tissues was demonstrated by the authors of most research, for instance Armstrong et al. (1971) using electron microscopy detected gammaretroviruses in the porcine kidney cell lines: PS, PK15, IB-RS-2 and SK6O.
Similarly, Suzuka et al. $(1985 ; 1986)$ identified C-type virus particles or unintegrated closed circular DNA of porcine retrovirus in swine cell line. Sypniewski et al. (2005) and Tacke et al. (2003) showed the presence of PERVs in porcine peripheral blood mononuclear cells (PBMCs) and fragments of the liver, kidney, and heart. A similar study was conducted by Prabha and Verghese (2009), authors demonstrated that PCR is a rapid and specific test for confirmation of the presence of PERVs. However, the most of these authors demonstrated only the presence of porcine endogenous retroviruses in

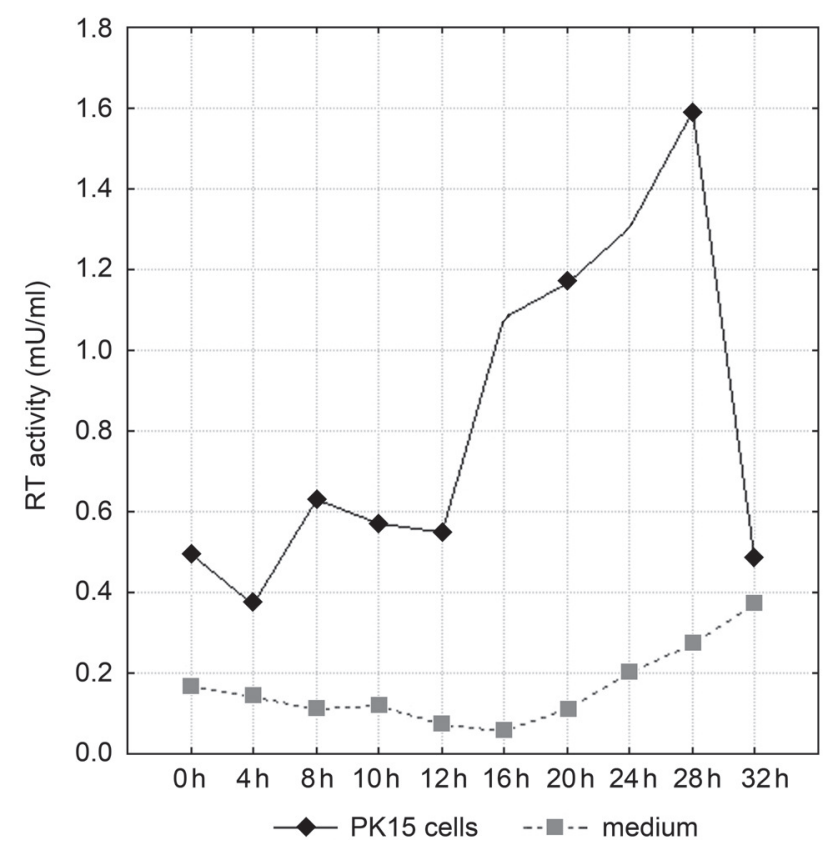

Fig. 2. The changes of PERV RT activity in PK15 cells and the culture medium in the successive hours of culturing 
examined tissues without quantitative assessment of PERV subtypes.

Our results revealed that the copy number of PERV A DNA and PERV A RNA was significantly higher than that of PERV B DNA and PERV B RNA in PK15 cells. Sypniewski et al. (2005), tested only DNA levels in porcine tissues and did not indicate significant differences in the copy number of PERV A and PERV B DNA. These authors showed that the copy number of another virus variant - PERV C DNA, is the lowest when compared with the level of $A$ and $B$ subtypes. Absence of PERV C in a PK15 cell line we used in our experiments (Ferrari et al., 2003) and in some porcine tissues can help to select organs for transplant. Elimination of tissues with PERV C can be beneficial for transplantation safety because the emergence of more infectious recombinant PERV A/C is limited (Bartosch et al., 2004; Harrison et al., 2004).

Cellular PERV RNA expression does not necessarily imply the release of viral particles; therefore RNA should also be prepared from cell culture supernatants. Like other authors (Tacke et al., 2003; Cunningham et al., 2004), we observed viral RNA both in the PK15 cell line and in the culture medium. It can be assumed that retroviruses integrated in the PK15 genome are capable to complete their life cycles and have the potential of causing infection. Kim et al. (2009) reported that PERVs produced by PK15 cells were able to infect human cells.

In our study, we observed a stable release of PERV particles over a period of 40 hours. We also found that the copy number of PERV A and B RNA in the culture medium fluctuated in a time dependent manner. The increase of PERV RNA in the supernatant may be caused by the release of virions from PK15 cells. At the time we initiated our study, only few published research reported the release of porcine endogenous retroviruses from porcine cells in time dependent fashion. Similarly to our results, Kim et al. (2009a) showed the stationary production of the PERV in host system. The studies performed by Tacke et al. (2003) and Cunningham et al. (2004) revealed that stimulation of porcine cells induced PERV release. Cheung and Bolin (2002) determined the kinetics of PCV2 (porcine circovirus type 2) replication in PK15 cells. These authors showed that the biosynthesis of viral antigens, RNA transcripts and progeny viruses increased in a time dependent manner during virus replication (Cheung and Bolin, 2002).

Further verification of PERV virion production was achieved by the detection of RT activity as a retroviral marker both in PK15 cells and cell culture supernatants. In our study, RT activity was detected in all tested PK15 cell samples and the supernatants of cultured cells. It was observed that RT activity fluctuated in a time dependent manner, corresponding with the changes of the copy number of PERV RNA. In the previous research, it was shown that the liver and muscle cellfree supernatants and the serum samples of pigs demonstrated high PERV RT activity, which implicated that PERVs were actively replicating (Liu et al., 2005). Only Tacke et al. (2003) and Han et al. (2011) determined the release of RT activity into the culture supernatant of porcine stimulated PBMCs and porcine hepatocytes, respectively, at different time intervals of culturing. The latter authors demonstrated that the RT activity was the highest after 10 hours and 2 days of culturing.

Our study on viral dynamics provides a timeline of PERVs release, which may be useful for potential preventive or antiviral strategies in xenotransplant recipients. Unfortunately, there is almost unexisting data on the life cycle of PERVs.

Summarizing, the copy numbers of PERV A and PERV B RNA, both in PK15 cells and in the culture medium, slightly changed in a time dependent manner. The monitoring of PERV release from the PK15 cell line may be useful for the characteristics of PERVs replication. Another important aspect of PERV production is assessment of its influence on the infection of human cells. Further study is required to define the pathogenic influence of porcine endogenous retroviruses on human cells. Such study can be used as a foundation to develop neutralization assays and antigen preparation for immunological testing of infections. Elimination of risks will enable the introduction of interspecies transplants to medicine.

\section{Acknowledgements}

This study was supported by the grant No. 120036 06/2009 (KNW-6-373/09) from Medical University of Silesia, Katowice, Poland and funded by The National Centre for Research and Development (NCBiR).

\section{References}

Armstrong J.A., J.S. Porterfield and A.T. De Madrid. 1971. C-type virus particles in pig kidney cell lines. J. Gen. Virol. 10: 195-198.

Bartosch B., D. Stefanidis, R. Myers, R. Weiss, C. Patience and Y. Takeuchi. 2004. Evidence and consequence of porcine endogenous retrovirus recombination. J. Virol. 78: 13880-13890.

Bösch S., C. Arnauld and A. Jéstin. 2000. Study of full-length porcine endogenous retrovirus genomes with envelope gene Polymorphism in a specific-Pathogen-Free Large White Swine Herd. J. Virol. 74: 8575-8581.

Cheung A.K. and S.R. Bolin. 2002. Kinetics of porcine circovirus type 2 replication. Arch. Virol. 147: 43-58.

Chomczynski P. and N. Sacchi. 1987. Single-step method of RNA izolation by acid guanidinium-thiocyanate phenol-chloroform extraction. Analitycal. Biochemistry. 162: 156-159.

Cozzi E., E. Bosio, M. Seveso, D. Rubello and E. Ancona. 2008. Xenotransplantation as a model of integrated, multidisciplinary research. Organogenesis, 5: 288-296.

Cunningham D.A., G.J. Dos Santos Cruz, X.M. FernándezSuárez, A.J. Whittam, C. Herring, L. Copeman, A. Richards and G.A. Langford. 2004. Activation of primary porcine endothelial 
cells induces release of porcine endogenous retroviruses. Transplantation, 77: 1071-1079.

Ferrari M., M.N. Losio, A. Corradi, S. Vittori and A. Tosini. 2003. Characterization of endogenous retroviruses in pig cell cultures. Vet. Res. Commun. 27: 703-705.

Fiorelli A.I., N.A. Stolf, P.M. Pego-Fernandes, J.L. Oliveira Junior, R.H. Santos, C.A. Contreras, D.D. Filho, J.J. Dinkhuysen, M.C. Moreira, J.A. Mejia and others. 2011. Recommendations for use of marginal donors in heart transplantation: Brazilian Association of Organs Transplantation guideline. Transplant. Proc. 43: 211-215. Garkavenko O., M.C. Croxson, M. Irgang, A. Karlas, J. Denner and R.B. Elliott. 2004. Monitoring for presence of potentially xenotic viruses in recipients of pig islet xenotransplantation. J. Clin. Microbiol. 42: 5353-5356.

Han B., X.L. Shi, J.Q. Xiao, Y. Zhang, X.H. Chu, J.Y. Gu, J.J. Tan, Z.Z. Gu and Y.T. Ding. 2011. Influence of chitosan nanofiber scaffold on porcine endogenous retroviral expression and infectivity in pig hepatocytes. World. J. Gastroenterol. 17: 2774-2780.

Harrison I., Y. Takeuchi, B. Bartosch and J.P. Stoye. 2004. Determinants of high titer in recombinant porcine endogenous retroviruses. J. Virol. 78: 13871-13879.

Heneine W., W.M. Switzer, J.M. Soucie, B.L. Evatt, V. Shanmugam, G.V. Rosales, A. Matthews, P. Sandstrom and T.M. Folks. 2001 Evidence of porcine endogenous retroviruses in porcine factor VIII and evaluation of transmission to recipients with hemophilia. J. Infect. Dis. 183: 648-652.

Jasinski A., R. Slomski, M. Szalata and D. Lipinski. 2006. The organ transplantation - a challenge for biotechnology (in Polish). Biotechnologia 72: 7-28.

Kim J.H., E.Y. Choi, E.S. Jung, Y. Kwon, D.S. Lee, D.Y. Hwang and E.S. Hwang. 2009. Characterization of Clones of Human Cell Line Infected with Porcine Endogenous Retrovirus (PERV) from Porcine Cell Line, PK15. Infection and Chemotherapy, 41: 1-8.

Kim N.Y., D. Lee, J. Lee, E.W. Park, W.W. Jung, J.M. Yang and Y.B. Kim. 2009a. Characterization of the replication-competent porcine endogenous retrovirus class B molecular clone originated from Korean domestic pig. Virus Genes. 39: 210-216.

Lechler R.I., M. Sykes, A.W. Thomson and L.A. Turka. 2005. Organ transplantation-how much of the promise has been realized? Nat. Med. 11: 605-613.

Levy M.F., T. Argaw, C.A. Wilson, J. Brooks, P. Sandstrom, H. Merks, J. Logan and G. Klintmalm. 2007. No evidence of PERV infection in healthcare workers exposed to transgenic porcine liver extracorporeal support. Xenotransplantation, 14: 309-315.

Liu Q., Z. Liu and E. Dalakas. 2005. Prevalence of porcine endogenous retrovirus in Chinese pig breeds and in patients treated with a porcine liver cell-based bioreactor. World. J. Gastroenterol. 11: $4727-4730$
Machnik G., D. Sypniewski, S. Gałka, T. Loch, D. Sołtysik, D. Błaszczyk and I. Bednarek. 2010. Changes of syncytin I expression level in HEK293 cells line after infection by porcine endogenous retroviruses (PERV) (in Polish). Scientific Review in Pharmacy, 7: 14-20.

McIntyre M.C., B. Kannan, G.I. Solano-Aguilar, C.A. Wilson and E.T. Bloom. 2003. Detection of porcine endogenous retrovirus in cultures of freshly isolated porcine bone marrow cells. Xenotransplantation 10: 337-342.

Moon H.J., S.J. Park, H.K. Kim, S.K. Ann, S. Rho, H.O. Keum and B.K. Park. 2010. Simultaneous detection and subtyping of porcine endogenous retroviruses proviral DNA using the dual priming oligonucleotide system. J. Vet. Sci. 11 (3): 269-271.

Prabha M.S. and S. Verghese. 2009. Polymerase chain reaction in detection of porcine endogenous retrovirus (PERV) from porcine tissues. Indian. J. Microbiol. 49: 68-71.

Salim A., M. Martin, C. Brown, P. Rhee, D. Demetriades and H. Belzberg. 2006. The Effect of a Protocol of Aggressive Donor Management: Implications for the National Organ Donor Shortage. J. Trauma, 61: 429-435.

Scobie L. and Y. Takeuchi. 2009. Porcine endogenous retrovirus and other viruses in xenotransplantation. Curr. Opin. Organ. Transplant. 14: 175-179.

Suzuka I., K. Sekiguchi and M. Kodama. 1985. Some characteristics of a porcine retrovirus from a cell line derived from swine malignant lymphomas. FEBS Lett. 183: 124-128.

Suzuka I., N. Shimizu, K. Sekiguchi, H. Hoshino, M. Kodama and K. Shimotohno. 1986. Molecular cloning of unintegrated closed circular DNA of porcine retrovirus. FEBS Lett. 198: 339-343.

Switzer W.M., R.E. Michler, V. Shanmugam, A. Matthews, A.I. Hussain, A. Wright, P. Sandstrom, L.E. Chapman, C. Weber, S. Safley and others. 2001. Lack of cross-species transmission of porcine endogenous retrovirus infection to nonhuman primate recipients of porcine cells, tissues, or organs. Transplantation, 71: 959-965.

Sypniewski D., G. Machnik, U. Mazurek, T. Wilczok, Z. Smorąg, J. Jura and B. Gajda. 2005. Distribution of Porcine Endogenous Retroviruses (PERVs) DNA in Organs of a Domestic Pig. Ann. Transplant. 10, 46-51.

Tacke S.J., V. Specke and J. Denner. 2003. Differences in Release and Determination of Subtype of Porcine Endogenous Retroviruses Produced by Stimulated Normal Pig Blood Cells. Intervirology, 46, $17-24$.

Valdes-Gonzalez R., L.M. Dorantes, E. Bracho-Blanchet, A. Rodríguez-Ventura, D.J. White. 2010. No evidence of porcine endogenous retrovirus in patients with type 1 diabetes after long-term porcine islet xenotransplantation. J. Med. Virol. 82: 331-334. 